\title{
Differences of patients with Angle class I type 1 profile before and after treated with removable orthodontic appliance
}

\author{
Novita Asti Nada*, N.R. Yuliawati Zenab*, Isnaniah Malik* \\ *Department of Orthodontics Faculty of Dentistry Universitas Padjadjaran
}

\begin{abstract}
Introduction: Children with bad habit and the persistence of deciduous teeth can caused malposition of anterior permanent teeth or Angle class I type 1 malocclusion. One of the curative treatment is removable orthodontic appliance. The purpose of this study was to determine the difference of dental arch width, overjet, and overbite in patients with Angle class I type 1 before and after treated with removable orthodontic appliance in Rumah Sakit Gigi dan Mulut (Dental Hospital) Universitas Padjadjaran. Methods: The research was conducted using 33 patient study models of Angle class I type 1 who were treated with removable appliance from year 2014 to 2015 in accordance with the criteria. Research method statistically analyzed with paired t-test sample. The dental arch width, overjet, and overbite were measured with caliper of patient study models before and after treatment with removable orthodontic appliance. Results: The difference value before and after treatment using removable orthodontic appliance were $2.8 \%$ for anterior dental arch width, 2.4\% for posterior dental arch width, $10.7 \%$ for overjet and $11 \%$ for overbite. Conclusion: The differences value of dental arch width, overjet, and overbite in patients with Angle class I type 1 before and after treated with removable orthodontic appliance showed only a little progress of the treatment caused by multiple factors.
\end{abstract}

Keywords: Angle class I type 1, Dental arch width, Overjet, Overbite

P-ISSN 1979-0201, e-ISSN 2549-6212 Available from:http://jurnal.unpad.ac.id/pjd/index

DOI:http://dx.doi.org/10.24198/pjd.vol29no1.11589

Submission: Jan 2017 Publishing: March 2017

\section{INTRODUCTION}

The development of science and technology, especially in orthodontics has been grown rapidly. The awareness of the importance of orthodontic treatment to fulfill the needs of aesthetics increased, because it can provide the significant treatment advances, but takes a long time and also requires patience, persistence, and good cooperation between the patient and the operator.
However, failure in treatment can also occur due to operator error and uncooperative patients, causing abnormal tooth position or malocclusion. Based on the report of Indonesian Basic Health Research, 14 provinces have oral problems of $25.9 \%$. The prevalence of malocclusion in Indonesia was very high around $80 \%$ of the population. ${ }^{1}$

This situation caused by the level of awareness of dental care is still low and some have bad habits, such as thumb sucking or other 
objects. The number and severity of malocclusion will continue to increase, therefore it can be done curative measures, one of them with orthodontic treatment. ${ }^{2}$ The data mentioned that the high prevalence of malocclusion was influenced by many factors; hereditary factors, teeth malposition, as well as environmental factors, such as, bad oral habit that may lead to crowded tooth, space between the teeth, improper bite between upper and lower jaw teeth that caused improper occlusal relationship. The malocclusion grouped into a classification. ${ }^{3}$

Angle malocclusion classified into three classes based on the occlusal relationship of first molars. Class I malocclusion have a normal relationship of the molars, but line of occlusion incorrect because of malposed teeth, rotations, or other causes. While in class II malocclusion, lower molar distally positioned relative to upper molar, and in class III malocclusion, lower molar mesially positioned relative to upper molar. ${ }^{4}$

The application of Angle classification can be seen from $^{5}$ research in SMP PGRI Dago Pakar, Bandung, that showed the high prevalence of malocclusion. The percentage of Angle class I was $73.7 \%$, and $13.3 \%$ for both Angle class II and Angle class III. Angle class I had the largest percentage, which explain many irregularities in the student's teeth include tooth crowding, protrusion, crossbite, and mesial drifting.

Deviations class I in most cases, especially at Rumah Sakit Gigi dan Mulut (Dental Hospital) Universitas Padjadjaran. occur because of the bad habit at children and the persistence of deciduous teeth that cause malposition of permanent anterior teeth during eruption, so the anterior teeth crowding, and this condition classified to Angle class I type 1. Angle class I malocclusion type 1 is position where the mesiobuccal cusp of first molars permanent maxillary located in the buccal groove of the first permanent mandibular molar, but the anterior teeth crowding with canine lies further to the labial (ectopic). ${ }^{6}$

Proffit $^{4}$ states that crowding, tooth rotation, and protrusion becomes a problem for some individuals. This can cause problems with oral functions such as mastication and speech, trauma, periodontal disease, tooth decay as well as aesthetic problem. Therefore, the orthodontic treatment needed to correct the alignment of dental arches and facial proportions. ${ }^{4}$ Orthodontic treatment aims to correct teeth and jaw shape in accordance with the normal, furthermore, ideal position. The normal and ideal position can be achieved since early age with preventive measures, such as giving enough nutrients, brushing teeth, use a space maintainer when tooth loss. When malocclusion occurs, orthodontic appliance needed to replace the anomaly position of teeth. ${ }^{7}$

Orthodontic appliance is a tool that can provide controlled power to the teeth and supporting tissues to produce changes in the position of the teeth. Orthodontic appliance consists of removable and fixed appliances. ${ }^{8}$

Ardhana $^{9}$ mentions that based on the function, the orthodontic appliance has advantages and disadvantages. Treatment with removable tool more widely known and used in Indonesia because it has a simple construction, easy to make, cheap, efficient, and the results are quite good, especially in a simple treatment to correct the width of the dental arch, overjet and overbite.

In Rumah Sakit Gigi dan Mulut (Dental Hospital) Universitas Padjadjaran. Angle class I type 1 found most often. Based on the number of patients treated at the Rumah Sakit Gigi dan Mulut (Dental Hospital) Universitas Padjadjaran. using removable orthodontic appliance, the amount of removable appliance progress in patients with Angle class I type 1 were unknown. The objective of the research was to know the progress of orthodontic treatment based on the differences of dental arch width, overjet and overbite in patients with Angle class I type 1 before and after treatment with removable orthodontic appliance in Rumah Sakit Gigi dan Mulut (Dental Hospital) Universitas Padjadjaran.

\section{METHODS}

This study using statistical analysis with paired sample t-test, to overview the differences of dental arch width, overjet, and overbite in patients with Angle class I type 1 before and after treatment with removable orthodontic appliance in Rumah Sakit Gigi dan Mulut (Dental Hospital) Universitas Padjadjaran.

Based on data taken from patients of Orthodontic Department at Rumah Sakit Gigi dan 
Mulut (Dental Hospital) Universitas Padjadjaran. status and mold, with inclusion criteria was minimum ten times activation of removable orthodontic appliance after three months of treatment. Whilst patient's status data, such as age, sex, and treatment progress was arranged and classified based on variables needed. The sample of this study was the study model or step model of patient with any differences before and after orthodontic treatment, using purposive sampling according to the criteria patient with Angle class I type 1 malocclusion with no extraction, using expansion screw and having cooperative behavior during treatment. The number of samples were $\geq 30$ using Central Limit Theorem to determine the number of samples to be normally distributed from a very large population.

First test done to measured the accuracy of the tool by measuring the model twice on the mold, then observed the difference between the first measurement with the second measurement to minimize errors. Then, analysis was conducted towards the mold for measurements of the width of the dental arch, overjet, and overbite.

The measurement of dental arch width was done by measuring the width of the dental arch anterior of the mold with a reference point in the lowest point of the transverse fissure of the first right premolar to the lowest point of the transverse fissure of the first left premolar (1424) using a caliper. ${ }^{10}$ After that, the width of the posterior dental arch on the mold of patients was measured with the intersection of the transverse fissure and buccal fissure of first right molar teeth to the meeting point of the transverse fissure and buccal fissure of first left molar tooth (16-26) using a caliper. Next, measured the width of dental arch on the model before and after treatment with expansion screws, and the results of measurement was recorded in millimeters. ${ }^{11}$

The measurement of overjet was done towards centric occlusion study model. The distance of incisal edge maxillary incisor teeth to the labial surfaces of incisor teeth of the mandibular was measured using a metal ruler or calipers, and the results of measurement was recorded in millimeters. The measurement of overbite was done also towards centric occlusion study model. The incisal edge of maxillary incisor teeth to the mandibular incisor teeth was projected, then marked with a pencil. After that, measured the distance from the projected incisal edge maxillary incisor teeth to the incisal edge incisor teeth of mandibular by using a caliper, and the results of measurement was recorded in millimeters.

\section{RESULT}

Summary of normality data test results using the Kolmogorov-Smirnov are presented in Table 1. Based on the results above, concluded that the entire group of data were normally distributed, the results shown by the $p$-value $>0.05$. Then, the comparative analysis was done using parametric analysis of paired sample t-test.

The research was conducted using 33 study model of patients of Angle class I type 1 who were treated with removable appliance. The average

Table 1. Normality test data

\begin{tabular}{ccccc}
\hline & \multicolumn{2}{c}{ Pre test } & \multicolumn{2}{c}{ Post test } \\
\cline { 2 - 5 } & P-value & Distribution & P-value & Distribution \\
\hline Ant dental arch width & 0.968 & Normal & 0.453 & Normal \\
Post dental arch width & 0.953 & Normal & 0.994 & Normal \\
Overjet & 0.753 & Normal & 0.441 & Normal \\
Overbite & 0.288 & Normal & 0.348 & Normal \\
\hline
\end{tabular}

Note: Normal if $p>0.05$

Table 2. Anterior dental arch width

\begin{tabular}{cccccc}
\hline Ant dental arch width & N & Mean (SD) & P-value & a & Conclusion \\
\hline Pre Test & 33 & $36.376(2.275)$ & 0.000 & 0.05 & Significant \\
Post Test & 33 & $37.412(2.406)$ & & & \\
\hline
\end{tabular}


Table 3. Posterior dental arch width

\begin{tabular}{cccccc}
\hline Post dental arch width & N & Mean (SD) & P-value & a & Conclusion \\
\hline Pre Test & 33 & $46.652(2.808)$ & 0.000 & 0.05 & Significant \\
Post Test & 33 & $47.791(2.733)$ & & & \\
\hline
\end{tabular}

Table 4. Overjet

\begin{tabular}{cccccc}
\hline Overjet & $\mathrm{N}$ & Mean (SD) & P-value & a & Conclusion \\
\hline Pre Test & 33 & $3.53(1.152)$ & \multirow{2}{*}{0.000} & 0.05 & Significant \\
Post Test & 33 & $3.152(1.121)$ & & & \\
\hline
\end{tabular}

Table 5. Overbite

\begin{tabular}{cccccc}
\hline Overbite & $\mathrm{N}$ & Mean (SD) & p-value & a & Conclusion \\
\hline Pre Test & 33 & $3.318(1.23)$ & 0.000 & 0.05 & Significant \\
Post Test & 33 & $2.955(1.201)$ & & & \\
\hline
\end{tabular}

Note: All data presented in Table 2, 3, 4, and Table 5 were having significant value if $p<0.05$

value of anterior dental arch width of patients before treatment with removable orthodontic appliance was $36.376 \mathrm{~mm}$. The value was $2.8 \%$ lower than the average value after treatment which was $37.412 \mathrm{~mm}$. Summary of test results are presented in Table 2.

Based on test results, $\mathrm{p}$-value $<0.05$, with a $95 \%$. Decided to reject $H_{0}$ and accept $H_{a}$, means there was a significant difference between the anterior dental arch width in patients with Angle class I type 1 before and after treatment with removable orthodontic appliance.

The average value of posterior dental arch width of patients before treatment with removable orthodontic appliance was $46.652 \mathrm{~mm}$. The value was $2.4 \%$ lower than the average value after treatment which was $47.791 \mathrm{~mm}$. Summary of test results are presented in the following Table 3.

Based on test results, $p$-value $<0.05$, with a $95 \%$. Decided to reject $\mathrm{H}_{0}$ and accept $\mathrm{H}_{\mathrm{a}}$, means there was a significant difference between posterior dental arch width in patients with Angle class I type 1 before and after treatment with removable orthodontic appliance.

The average overjet value of 33 patient study models before treatment with removable orthodontic appliance was $3.530 \mathrm{~mm}$. The value was $10.7 \%$ higher than the average value after treatment which was $3.152 \mathrm{~mm}$. Summary of test results are presented in Table 4.
Based on test results, $\mathrm{p}$-value $<0.05$, with a $95 \%$. Decided to reject $H_{0}$ and accept $H_{a}$, means there was a significant difference between overjet of Angle class I type 1 before and after treatment with removable orthodontic appliance.

The average overbite value of 33 patients study models before treatment with removable orthodontic appliance was $3.318 \mathrm{~mm}$. The value was $11 \%$ higher than the average value after treatment which was $2.955 \mathrm{~mm}$. Summary of test results are presented in the following Table 5.

Based on test results, $\mathrm{p}$-value $<0.05$, with a $95 \%$. Decided to reject $H_{0}$ and accept $H_{a}$, means there was a significant difference between Angle class I type I patients overbite before and after treatment with removable orthodontic appliance.

\section{DISCUSSION}

The results showed significant differences between the dental arch width, overjet, and overbite in patients with Angle class I type 1 before and after treatment with removable orthodontic appliance in Rumah Sakit Gigi dan Mulut (Dental Hospital) Universitas Padjadjaran. Differences occurs because of the progress of treatment with removable orthodontic appliance.

The difference of anterior dental arch width before and after removable orthodontic appliance was $1.036 \mathrm{~mm}$, whilst posterior dental arch width 
difference was $1.139 \mathrm{~mm}$. Dental arch width can be corrected using expansion screw to expand the arch. Expansion screw works by expanding the arch toward the lateral, anterior or both and more commonly used for the upper jaw. Lateral expansion will increase the basal structure of upper jaw approximately $2 \mathrm{~mm}$ between 7 and 15 years old. $\mathrm{Kim}^{12}$ states that there were significant differences between anterior and posterior dental arch width. Expansion screws laterally to the first premolar teeth can be used to widen the arch to obtain space for the component to correct the teeth. Another study states that the intermolar width relatively fixed and stable along period of growth and observation in various ethnic groups also showed similar results.

The difference of overjet was $0.378 \mathrm{~mm}$. Overjet can be corrected by labial bow to retract anterior teeth and maintain the dental arch. Activation of labial bow used to move teeth 1 $\mathrm{mm}$ towards the palatal or lingual. The difference of overbite was $0.363 \mathrm{~mm}$. Overbite must be corrected before the overjet correction to avoid the occurrence of traumatic occlusion. ${ }^{13}$ The upper jaw can shift 2-3 mm at the age of 3-18 years, with drastic changes happens more in male than female. Therefore, the difference in the width of the dental arch, overjet and overbite is more significant for patients in growth period. From two of three individuals, changes in overjet and overbite exceed $\pm 1 \mathrm{~mm}$ in 12 to 20 years old. ${ }^{4}$

\section{CONCLUSION}

There were significant differences in anterior dental arch width (2.8\%), posterior dental arch width $(2.4 \%)$, overjet $(10.7 \%)$ and overbite $(11 \%)$ in Angle class 1 type 1 patients before and after treatment with removable orthodontic appliance in Rumah Sakit Gigi dan Mulut (Dental Hospital) Universitas Padjadjaran. But the difference value showed only little progress of the removable orthodontic appliance treatment. The progress of removable orthodontic appliance treatment was influenced by the growth and development of dental arch, the ability of the operator, active components equipments such as expansion screw and labial bow, and cooperative attitude of the patient.

\section{REFERENCES}

1. National Basic Health Research (RISKESDAS) Dental health. Jakarta: The National Institute of Health Research and Development Ministry of Health Republic of Indonesia; 2013. p. 111.

2. Laguhi VA. Gambaran maloklusi dengan menggunakan hmar pada pasien di Rumah Sakit Gigi dan Mulut Universitas Sam Ratulangi Manado. J e-GiGi (eG) 2014; Juli-Des(2):2.

3. Phulari BS. History of orthodontics. New Delhi: Jaypee Brothers Medical Publishers; 2013. p. 15.

4. Profitt WR, Fields HW, Sarver DM. Contemporary orthodontics. $5^{\text {th }}$ ed. St. Louis: Mosby Elsevier; 2013. p. 2-3,10-11,14,347-8, 357 .

5. Balakrishnan P. Comparison of the characteristic of malocclusion based on Angles classification among disabled children and the nondisabled children. 2010 [Cited 20 Jan 2016]. Available from: http: / / kandaga.unpad. ac.id/Record/IOS1.18936.

6. Zenab Y. Perawatan maloklusi kelas I Angle Tipe 2, Makalah FKG Universitas Padjadjaran. 2010. p. 7. [Cited 2015 Nov 21]. Available from: http://pustaka.unpad.ac.id/archives/ 90121/.

7. Singh G. Textbook of orthodontics. $3^{\text {rd }}$ ed. New Delhi: Jaypee Brothers Medical Publishers; 2015. p. 613-18.

8. Salzmann A. Practice of orthodontics. Philadelphia: Am J Orthod 1966;52(8):617-18.

9. Ardhana W. Alat ortodontik lepasan. Yogyakarta: Universitas Gadjah Mada; 2011. p. 1-3.

10. Rakosi T, Irmtrud J, Graber TM. Color atlas of dental medicine (Orthodontic-diagnosis). New York: Thieme; 1993. p. 166-7, 208.

11. Kim BI, Bayome M, Baek SH. Comparison of overjet among 3 arch types in normal occlusion. Europ J Orthod 2011;139(3):253-60.

12. Luther F, Nelson-Moon Z. Orthodontic retainers and removable appliances: Principles of design and use. Oxford: Willey-Blackwell;2013. p. 151. 